METAgraphias: letra F de \#foulipo (criação potencial) v.2 n.3 setembrol2017

Com chumbos de todos os tipos • Stênio Junior (stttir@outlook.com)

\title{
Com chumbos de todos os tipos
}

Stênio Junior

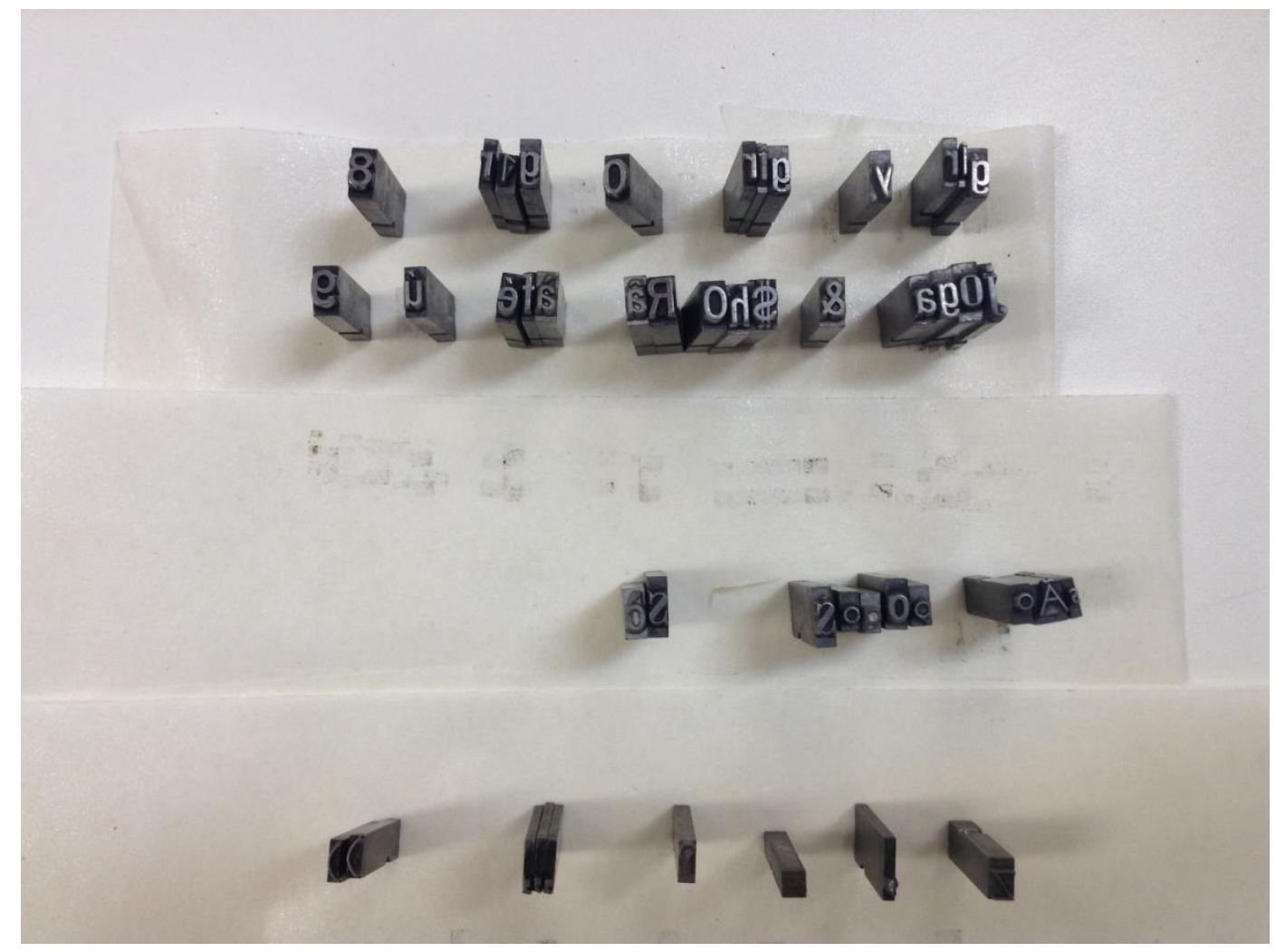


METAgraphias: letra F de \#foulipo (criação potencial) v.2 n.3 setembrol2017 Com chumbos de todos os tipos • Stênio Junior (sttti@@outlook.com)

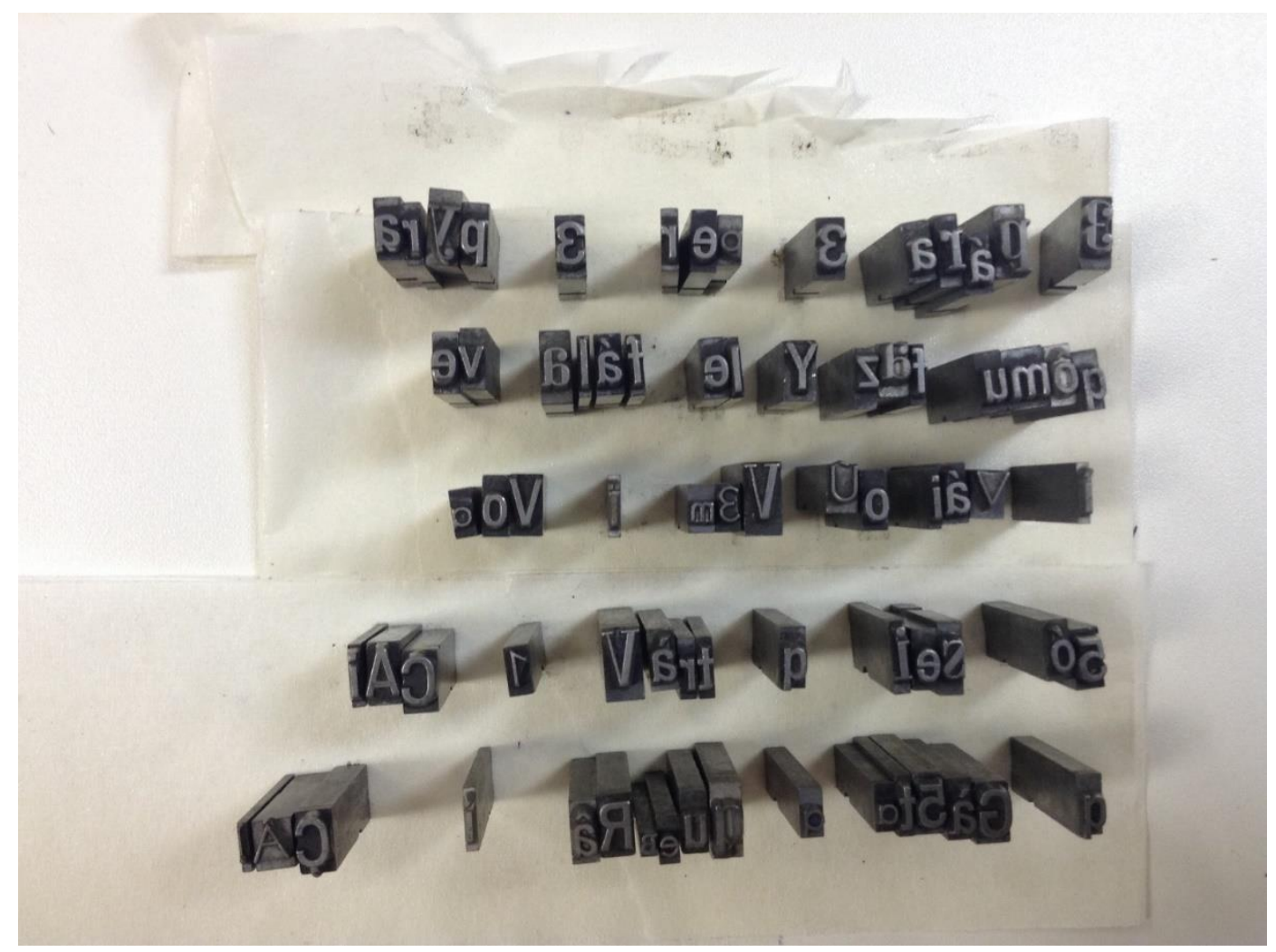




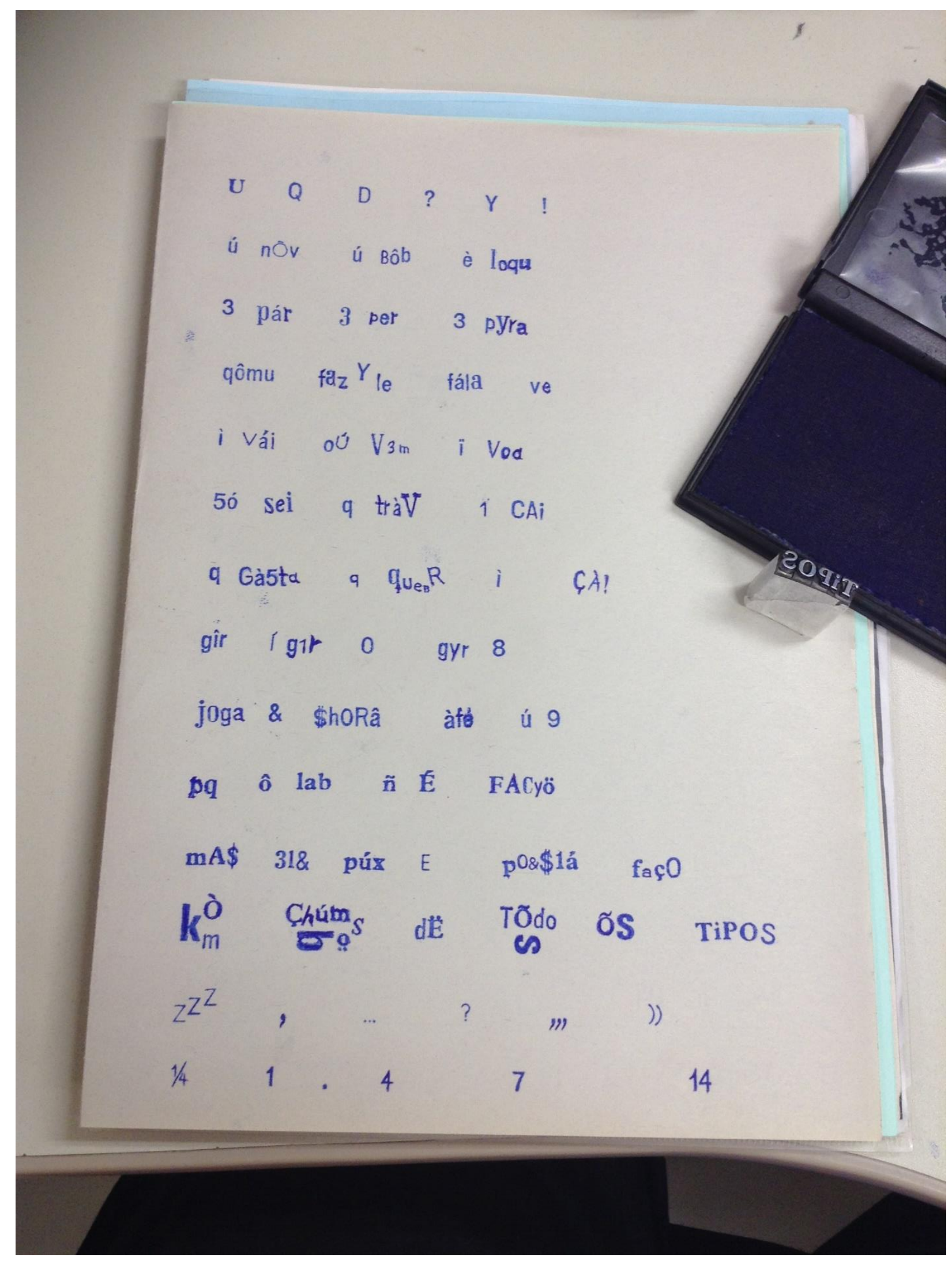

